\title{
Thin and subvisible cirrus and contrails in a subsaturated environment
}

\author{
M. Kübbeler ${ }^{1,5}$, M. Hildebrandt ${ }^{1,6}$, J. Meyer ${ }^{1}$, C. Schiller ${ }^{1}$, Th. Hamburger ${ }^{2}$, T. Jurkat ${ }^{2}$, A. Minikin ${ }^{2}$, A. Petzold ${ }^{2}$, \\ M. Rautenhaus ${ }^{2}$, H. Schlager ${ }^{2}$, U. Schumann ${ }^{2}$, C. Voigt $^{2,3}$, P. Spichtinger ${ }^{3}$, J.-F. Gayet ${ }^{4}$, C. Gourbeyre ${ }^{4}$, and \\ M. Krämer ${ }^{1}$ \\ ${ }^{1}$ Forschungszentrum Jülich, Inst. for Energy and Climate Research, IEK-7, Jülich, Germany \\ ${ }^{2}$ DLR Oberpfaffenhofen, Inst. Atmos. Physics, Weßling, Germany \\ ${ }^{3}$ Univ. Mainz, Inst. Atmos. Physics, Mainz, Germany \\ ${ }^{4}$ Univ. Blaise Pascal, LaMP, Clermont-Ferrand, France \\ ${ }^{5}$ now at: ETH Zürich, Inst. Atmos. \& Climate, Zürich, Switzerland \\ ${ }^{6}$ now at: IUTA, Air Quality Dep., Duisburg, Germany
}

Received: 9 November 2010 - Published in Atmos. Chem. Phys. Discuss.: 22 December 2010

Revised: 31 May 2011 - Accepted: 8 June 2011 - Published: 22 June 2011

\begin{abstract}
The frequency of occurrence of cirrus clouds and contrails, their life time, ice crystal size spectra and thus their radiative properties depend strongly on the ambient distribution of the relative humidity with respect to ice $\left(\mathrm{RH}_{\text {ice }}\right)$. Ice clouds do not form below a certain supersaturation and both cirrus and contrails need at least saturation conditions to persist over a longer period. Under subsaturated conditions, cirrus and contrails should dissipate. During the mid-latitude aircraft experiment CONCERT 2008 (CONtrail and Cirrus ExpeRimenT), $\mathrm{RH}_{\text {ice }}$ and ice crystals were measured in cirrus and contrails. Here, we present results from $2.3 / 1.7 \mathrm{~h}$ of observation in cirrus/contrails during 6 flights. Thin and subvisible cirrus with contrails embedded therein have been detected frequently in a subsaturated environment. Nevertheless, ice crystals up to radii of $50 \mu \mathrm{m}$ and larger, but with low number densities were often observed inside the contrails as well as in the cirrus. Analysis of the meteorological situation indicates that the crystals in the contrails were entrained from the thin/subvisible cirrus clouds, which emerged in frontal systems with low updrafts. From model simulations of cirrus evaporation times it follows that such thin/subvisible cirrus can exist for time periods of a couple of hours and longer in a subsaturated environment and thus may represent a considerable part of the cirrus coverage.
\end{abstract}

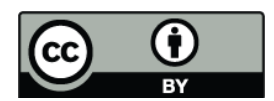

Correspondence to: $\mathrm{M}$. Krämer (m.kraemer@fz-juelich.de)

\section{Introduction}

In the past decade, ice supersaturated regions in the upper troposphere were a focus of atmospheric research (Gierens et al., 1999). These regions cover large parts of the tropopause region (Gierens and Spichtinger, 2000; Spichtinger et al., 2003; Gettelman et al., 2006). They are potential formation regions for cirrus clouds, since ice formation needs a certain ice supersaturation (Koop, 2004; DeMott et al., 2003). In addition, contrails, i.e. ice clouds formed directly by anthropogenic injections, can appear and evolve to aviation induced cirrus in supersaturated air. Both cirrus and contrails are known to impact the Earth's climate (Solomon et al., 2007; Burkhardt et al., 2010) but estimates of this impact are still deficient. To improve the estimates requires advanced knowledge of cirrus and contrail ice microphysics and radiative properties, as well as the global distribution of upper-tropospheric ice supersaturation (Forster and Rogers, 2008).

Against this background, in situ observations of cirrus and contrails in the mid-latitude tropopause region were performed during the field campaign CONCERT (CONtrail and Cirrus ExpeRimenT, Voigt et al., 2010). The measurements have been performed above Germany and Central Europe with the DLR research aircraft Falcon from 22 October to 20 November 2008.

Here, we analyze cirrus and contrails that are probed during the CONCERT field experiment. We focus on $\mathrm{RH}_{\text {ice }}{ }^{-}$ measurements and microphysical properties. The instruments are described in Sect. 2.

Published by Copernicus Publications on behalf of the European Geosciences Union. 
The observed cirrus clouds were mostly thin or subvisible to the eye from aircraft (for definition of visibility see Sect. 3.1). They were detected in subsaturated environments, the contrails were mostly embedded in these clouds. However, both cirrus and contrails showed size distributions including ice crystals up to $50 \mu \mathrm{m}$ radius and larger (see Sect. 3.1 and Voigt et al., 2010). In Sect. 3.2 we evaluate in more detail these conditions by an extensive analysis of the flight performed on 17 November 2008.

In addition, we performed a model case study, tracking the evolution of the cirrus cloud observed during the 17 November flight by using the kinetical microphysical model MAID (see Sect. 4.1). The simulations suggest that the large ice crystals originate from thin to subvisible frontal cirrus clouds formed at very low vertical velocities and that they needed several hours to grow to the observed sizes. The large crystals found in the contrails are most probably entrained from the surrounding cirrus.

Extended idealized model simulations of ice crystal growth and evaporation times (see Sect. 4.2) show that thin/subvisible ice clouds ${ }^{1}$ consisting of only few, but large ice crystals can survive in a subsaturated environment for several hours. Such long lifetimes of ice crystals in subsaturation are of relevance for the atmosphere because e.g. the seeding of lower-level clouds by precipitating ice crystals depends on their fall distances and further, sublimation of ice crystals from cumulonimbus anvils supplies the upper troposphere with water vapor (Nelson, 1998).

Altogether, the measurements and model simulations presented here highlight that not only investigation of the global distribution of upper tropospheric supersatured regions is important in terms of cirrus cloud occurrence, but that subsaturated areas containing thin/subvisible cirrus should likewise be considered.

\section{Aircraft measurements}

A set of instruments was installed on board the research aircraft DLR Falcon during CONCERT to measure the properties of cirrus clouds, contrails and their ambient environment. The base of the campaign was located at Oberpfaffenhofen near Munich, Germany, and it took place in October and November 2008. The measurements presented in this study were performed during six flights over Germany and neighboring states i.e. Denmark, United Kingdom, Ireland, Low Countries, France and Austria. Voigt et al. (2010) provides a broad overview over the CONCERT campaign and a detailed description of the participating instruments. For more detail we refer to this study and give here only a brief description of the instruments used for this study.

\footnotetext{
${ }^{1}$ the term thin/subvisible is used in the following to describe cirrus which are thin or subvisible by eye from aircraft (see also Sect. 3.1).
}

\subsection{Water vapour}

Measurements of water vapour inside and outside of ice clouds have been obtained by the high precision hygrometer FISH (Fast In situ Stratospheric Hygrometer, Zöger et al., 1999; Schiller et al., 2008). The instrument was developed at the Research Center Jülich and is based on the Lyman$\alpha$ photofragment fluorescence technique with a measurement frequency of $1 \mathrm{~Hz}$. Using a backward facing inlet enables to exclude ice crystals, thus sampling water in the gas phase $\left(\mathrm{H}_{2} \mathrm{O}_{\text {gas }}\right)$. We derived $\mathrm{RH}_{\text {ice }}$-the ratio of the ambient amount of water vapour to the saturation water vapour over an ice surface- by using the empirically derived expression of Marti and Mauersberger (1993) as function of the ambient temperature and pressure. Both variables are received from the meteorological dataset of the DLR Falcon. The uncertainties of the variables are $\Delta T=0.5 \mathrm{~K}, \Delta p=0.5 \mathrm{hPa}$, $\Delta \mathrm{H}_{2} \mathrm{O}_{\text {gas }}=6 \%$ or at least $0.3 \mathrm{ppmv}$, yielding an overall uncertainty of $\mathrm{RH}_{\text {ice }}$ of $\approx 10 \%$.

To ensure the high accuracy of the $\mathrm{H}_{2} \mathrm{O}$ measurements, FISH is calibrated before and after the experiment and between the single flights by using a calibration bench including a frost point hygrometer (MBW DP30) as reference.

As will be seen in Sect. 3.1, $\mathrm{RH}_{\text {ice }}$ around $90 \%$ are often detected during the CONCERT campaign. To make sure that there is no bias in the water measurements, we performed extensive calibrations after the campaign in addition to the frequent calibrations of the FISH instrument, confirming the high accuracy of the measurements.

\subsection{Ice crystals}

Several instruments were installed on board the DLR Falcon to measure the microphysical and optical properties of ice clouds. In this study we use a polar nephelometer (PN) operated by Laboratoire de Meteorologie Physique (LaMP) to obtain information about the presence of ice crystals. PN measures the scattering phase function of particles ranging from a few micrometers to 800 microns and provides calculated optical properties, i.e. the extinction coefficient (Gayet et al., 2002a). The accuracy of the extinction coefficient is estimated to be within $25 \%$ (Gayet et al., 2002b).

Further, a Forward Scattering Spectrometer Probe (FSSP300, manufactured by Particle Measuring System, PMS and operated by DLR, Petzold et al., 1997) was employed to measure the size distribution in the size range $0.3-$ $18 \mu \mathrm{m}$ by detecting the light scattered by the particles. The size spectra measured by the FSSP 300 were analysed assuming nonspherical ice particles $(m=1.31)$ of aspect ratio 0.75 . The assumption on ice crystal shape generates uncertainties in the sizing. In the sub- $\mu \mathrm{m}$ range, differences between spherical and spheroidal particles are of the order of $50 \mathrm{~nm}$ in diameter, while this difference may increase to $1 \mu \mathrm{m}$ in the sub- $10 \mu \mathrm{m}$ range, and to $>2 \mu \mathrm{m}$ in the super- $10 \mu \mathrm{m}$ range (estimates are based on Borrmann et al., 2000). The 
uncertainty of the ice crystal number concentrations, caused by the inaccurateness in determining the particle sampling volume and sampling statistics errors, is in the order of $100 \%$ for contrail and cirrus encounters with number concentrations $>0.1 \mathrm{~cm}^{-3}$.

Large ice crystals $>50 \mu \mathrm{m}$ were measured by means of a Cloud Particle Imager (CPI, manufactured by Spec Inc., operated by LaMP), recording the ice crystal shape with a resolution of $2.3 \mu \mathrm{m}$ pixel size. The uncertainties on CPI derived microphysical parameters are $25 \%$ and $50-75 \%$ for particle size and concentration, respectively (Gayet et al., 2002b).

Shattering of ice crystals at the inlets of the instruments cannot be completely excluded, though the impact of shattered ice crystals on the total number or size distribtuion is minor at temperatures lower than $\sim 240 \mathrm{~K}$, because the ice crystals are typically not as large as at higher temperatures, as Krämer et al. (2009) and de Reus et al. (2009) discussed. The size and amount of the fragments of shattered ice crystals can not be estimated for the probes used here by interrival time correction (see Korolev et al., 2011, and references herein) because those times are not recorded.

\section{$2.3 \quad \mathrm{NO}_{\mathrm{y}}$}

Contrails are typically characterized by a high concentration of $\mathrm{NO}_{\mathrm{x}}$, carbon dioxide, total particle and soot particle numbers (Schumann et al., 1998). Here, we used $\mathrm{NO}_{\mathrm{y}}$ for contrail identification. Using two backward facing inlets, nitric oxide (NO) and mainly gas phase reactive nitrogen $\mathrm{NO}_{\mathrm{y}, \mathrm{g}}$ $\left(=\mathrm{NO}+\mathrm{NO}_{2}+\mathrm{HONO}+\mathrm{HNO}_{3}+2 \mathrm{~N}_{2} \mathrm{O}_{5}+\mathrm{PAN}+\ldots\right) \quad$ were measured by a $\mathrm{NO}_{\mathrm{y}}$ detector based on the chemiluminescence technique (Schlager et al., 1997; Voigt et al., 2006). The instrument has a detection limit of 1 and $5 \mathrm{pmol} \mathrm{mol}^{-1}$ for $\mathrm{NO}$ and $\mathrm{NO}_{\mathrm{y}}$ respectively and an accuracy of $8 \%$ at a time resolution of $1 \mathrm{~s}$.

\subsection{Cirrus and contrail detection}

To relate a certain data point to a cirrus cloud, the first two of the criteria listed below have to be fulfilled. For a contrail event, all four conditions have to be met:

1. The scattering phase function measured by the PN has to be nonzero to ensure the existence of ice crystals.

2. The FSSP also has to detect ice crystals $>1.5 \mu \mathrm{m}$ radius to ensure the PN measurements.

3. The $\mathrm{NO}_{\mathrm{y}}$ concentration of that data point has to exceed $\mathrm{NO}_{\mathrm{y} \text {,thresh }}$, set to 0.2 ppbv by deliberating the background values of $\mathrm{NO}_{\mathrm{y}}$.

4. The temperature has to be below $240 \mathrm{~K}$ to exclude warm plumes from air pollution at ground level.

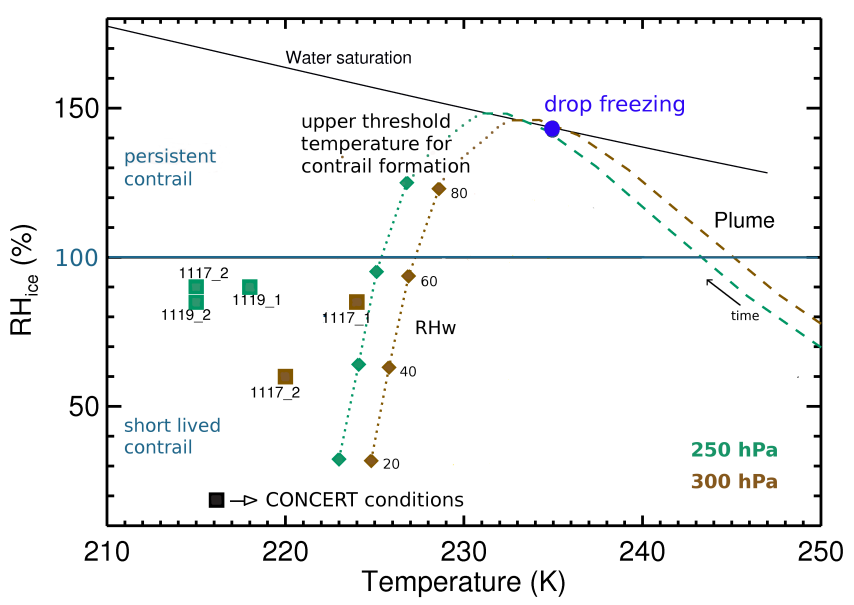

Fig. 1. Ambient temperature and humidity conditions during four CONCERT flights (rectangles, colored by pressure, labeled with mmdd_flightnumber) and calculated upper threshold temperatures for contrail formation for the same pressures and varying $\mathrm{RH}_{\mathrm{W}}$ (dotted lines with diamonds; $\mathrm{RH}_{\mathrm{W}}$ : relative humidity wrt water): the contrail formation criterion was well fulfilled during the flights. Dashed lines: calculated evolution of aircraft plume temperatures and $\mathrm{RH}_{\mathrm{ice}}$ until drop formation and freezing for the two mean ambient pressures.

As an example for contrail identification, the conditions of five contrails probed during CONCERT are shown in Fig. 1: the temporal evolution of $\mathrm{RH}_{\text {ice }}$ with temperature inside of the aircraft plumes until drop formation and freezing (dashed lines) is calculated as a function of the prevailing ambient pressure $(250 \mathrm{hPa}$ : moos, $300 \mathrm{hPa}$ : brown). Further, the threshold temperatures for contrail formation, i.e. the highest temperature where the available moisture from ambient air and aircraft is sufficient to reach water saturation in the plume, are also calculated after Jensen et al. (1998) and Schumann (1996) for the ambient pressures and various relative humidities over liquid water $\left(\mathrm{RH}_{\mathrm{w}}\right.$, coloured diamond-dotted lines). The ambient temperatures (rectangles, colored by pressure) were well below the threshold temperatures, thus contrails form when flying in this regions. $\mathrm{RH}_{\text {ice }}$ was below saturation, thus most likely the contrails were short lived, since they quickly evaporate in subsaturated air (Schröder et al., 2000).

\section{Cirrus and contrail observations}

\subsection{Relative humidity, ice and visibility}

$\mathrm{RH}_{\mathrm{ice}}$ and ice crystal properties of cirrus and contrails were observed during six flights (listed in the caption of Fig. 2). $0.9,2.3$ and $1.7 \mathrm{~h}$ of observation were spent in clear sky, cirrus and contrails, respectively, in the temperature range of $210-230 \mathrm{~K}$ at altitudes between $8-11 \mathrm{~km}$. All contrails were young, having a contrail age between 1 and $5 \mathrm{~min}$. The 


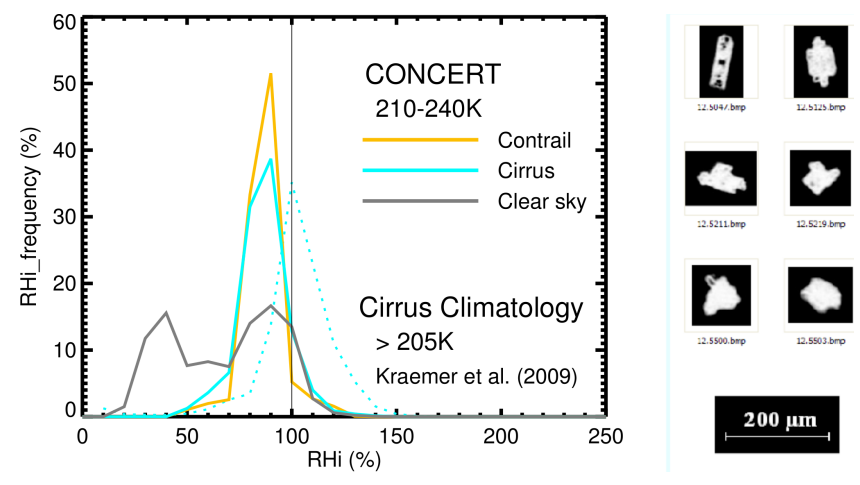

Fig. 2. Left panel: Frequency of occurrence of $\mathrm{RH}_{\text {ice }}$ in contrails, cirrus and clear sky during CONCERT (solid lines) and for a broad range of cirrus conditions (dotted line, from Krämer et al., 2009, $5.6 \mathrm{~h}$ observation time, 28 flights). CONCERT sampling times: clear sky $0.9 \mathrm{~h}$, cirrus $2.3 \mathrm{~h}$, contrails $1.7 \mathrm{~h}$, Flight dates: 29 October. (1 flight), 17 November (2 flights), 19 November (2 flights), 20 November (1 flight). Right panel: large ice crystals observed inside of the cirrus and contrails during CONCERT.

contrail age was obtained by the distance between the probed airliner and the research aircraft FALCON after Febvre et al. (2009) taking into account the wind drift at measured wind velocities and directions (Voigt et al., 2010). The predominating weather situation was characterized by a trough meandering over Europe connected with frontal zones that regularly crossed through central Europe.

The left panel of Fig. 2 depicts the frequency distributions of $\mathrm{RH}_{\text {ice }}$ in cirrus, contrails and in the ambient air. It can be seen that the most frequent $\mathrm{RH}_{\text {ice }}$ is always $90 \%$, i.e. the slightly sub-saturated conditions in the cirrus and contrails mirror the clear sky conditions, since air from the environment is continuously entrained into them. Both cirrus and contrails are in the evaporation stage. In contrast, the frequencies of occurrence of $\mathrm{RH}_{\text {ice }}$ in cirrus clouds sampled during 28 flights $(15.9 \mathrm{~h})$ in differing meteorological situations (dotted line, from Krämer et al., 2009) peak at $100 \%$ as expected. The lower peak of the $\mathrm{RH}_{\text {ice }}$ frequencies is found during CONCERT because during all flights comparable situations -namely evaporating frontal cirrus- were probed. However, note that the uncertainty of the $\mathrm{RH}_{\text {ice }}$ measurement is $10 \%$, i.e. the subsaturation could have been lesser.

The cirrus clouds show maximum ice water contents (IWC) - derived from ECMWF (European Center for Medium-Range Weather Forecasts) analysis fields - of about 3, 5, 4 and 4 ppmw (1st and 2nd flight, 17 November; 1st and 2nd flight, 19 November, respectively). This means that they were thin/subvisible when compared to 210 (9) ppmw, the maximum (median) IWC observed at $225 \mathrm{~K}$ by in-situ measurements during 52 flights (Schiller et al., 2008). Nevertheless, large ice crystals up to sizes of $50 \mu \mathrm{m}$ in radius and larger were detected inside of the subsaturated cirrus and contrails during the flights on 17 and 19 November, which is illustrated in the right panel of Fig. 2. More detailed information on the ice crystal numbers and sizes is given in the next section and also in Voigt et al. (2010) (their Fig. 10).

Figure 3 gives a visual impression of the contrails placed in the thin/subvisible cirrus: only during the 1st flight on 17 November a cirrus is perceptible by eye. Kärcher (2002) describes a criterion determining cirrus visibility which is based on satellite observations: if the optical extinction $E$ of the cirrus cloud at the wavelength of $1 \mu \mathrm{m}(E(\lambda=1 \mu \mathrm{m}))$ is smaller than $2-3 \times 10^{-5} \mathrm{~m}^{-1}$, then the cirrus is regarded as subvisible (see Eqs. (18-20) in Kärcher, 2002). The extinction $E$ can be determined only from the total number concentration and mean size of ice crystals, i.e. without knowing the thickness of the cirrus layer, by using Eqs. (16) and (19) provided by Kärcher (2002). Calculating this quantity for the large ice crystals detected during the four CONCERT flights yields to $1.3-8 \times 10^{-5} \mathrm{~m}^{-1}$, i.e. around the edge of visibility. But, for the smaller ice crystals $E(\lambda=1 \mu \mathrm{m})$ ranges between $3-6 \times 10^{-4} \mathrm{~m}^{-1}$. Thus, all cirrus should have been visible based on this measure and indeed were visible from satellite, as shown in Fig. 4 for two flights. The same results when calculating the cirrus optical depth (after Immler et al., 2008) for a cirrus thickness of 750-1600 m, taking into account that the visibility threshold from ground bye eye is 0.03 (Sassen et al., 1989): for the larger crystals the optical depth is 0.010.1 (around the edge of visibility) and for the smaller 0.1-4 (visible). Apparently, cirrus visibility by eye from aircraft which is the criterion for their in-situ detection- is worse than their visibility from satellites or human eye from ground.

\subsection{Flight 17 November 2008: chasing contrail of Airbus A340}

To understand the conditions leading to the observed situations of ice crystals with sizes of $50 \mu \mathrm{m}$ and larger in subsaturated cirrus clouds and contrails, we investigate in more detail the 1st flight on 17 November 2008 from 11:00 to 13:20 UTC.

\subsubsection{Flight description}

Figure 5 (top panel) illustrates the flight path, indicating the detection of three cirrus sections (turquoise, ice is detected as described in Sect. 2.4), where the second includes the contrail (orange) of an Airbus A340. The contrail chasing took place above northern Germany near Hamburg and lasted about $6 \mathrm{~min}$. In the bottom panel of Fig. 5 temperature, pressure, altitude and $\mathrm{RH}_{\text {ice }}$ measured along the flight path are shown. The three cirrus periods were detected between 11:40-11:55 UTC, 12:10-12:40 UTC and a short period around 13:00 UTC. $\mathrm{RH}_{\text {ice }}$ inside of the cirrus greatly varies between 45-125\% during the flight, the A340 contrail was detected in a subsaturated part ( $\left.\mathrm{RH}_{\text {ice }} 70-95 \%\right)$. 


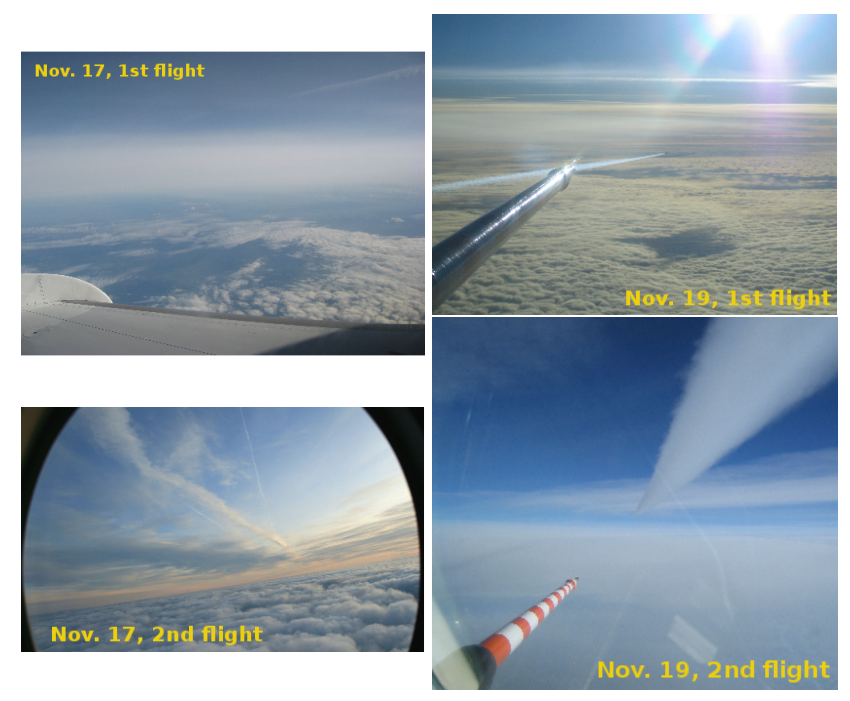

Fig. 3. Pictures of situations with contrails embedded in subvisible cirrus and subsaturated air (upper left: 17 November, 1st flight, lower left: 17 November, 2nd flight, upper right: 19 November, 1st flight, lower right: 19 November, 2nd flight).

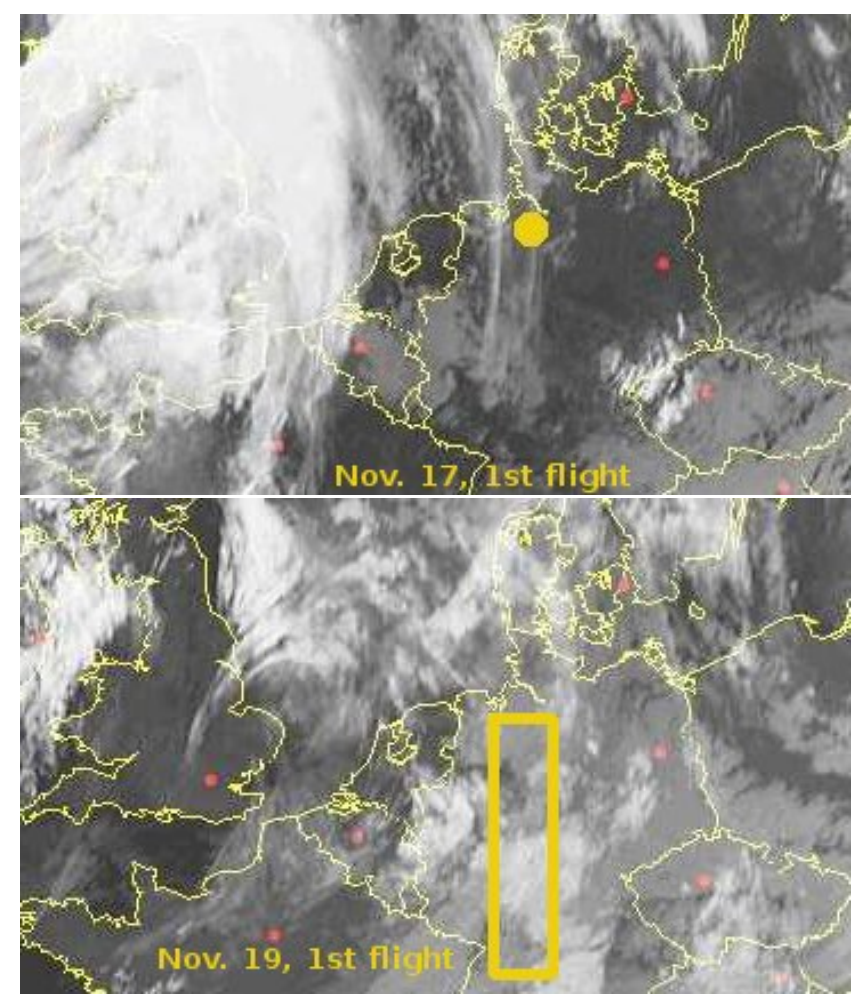

Fig. 4. Infrared satellite images corresponding to pictures shown in Fig. 3. The yellow rectangle denotes the flight area of both flights, the yellow dot in the upper panel the detection of the contrail discussed in Sect. 3.2 (Sat24.com, Source EUMETSAT).

\subsubsection{Vertical structure of cirrus and contrail}

The first and top cirrus layer was detected by DLR Falcon at an altitude of $9.7 \mathrm{~km}$ (Fig. 6, top panel), temperatures of $216.5-218.5 \mathrm{~K}$ and $\mathrm{RH}_{\text {ice }}$ between $55-125 \%$ (bottom panel). The second cirrus layer in the temperature range 220-225 K was found at altitudes $8.8-9.4 \mathrm{~km}$ with a supersaturated part between 9.1 and $9.4 \mathrm{~km}$ and a subsaturated area at $8.8_{-}$ $9.1 \mathrm{~km}$. The third cirrus, found around $8.5 \mathrm{~km}$, show temperatures between $225.5-227.5 \mathrm{~K}$, while $\mathrm{RH}_{\text {ice }}$ range from 85$115 \%$. Above and below these layers the air is quite dry. The contrail of the A340 with a vertical extent of $\approx 200 \mathrm{~m}$ was detected in the subsaturated bottom of the second cirrus. Here, $\mathrm{RH}_{\text {ice }}$ ranges from 75 to $90 \%$, the contrail age is estimated as 60 to $180 \mathrm{~s}$.

The number concentrations of the ice crystals sampled in the second cirrus layer including the contrail are shown in Fig. 7 for the two measured size intervals: the smaller ice crystals, $R_{\text {ice }}=1.5-18 \mu \mathrm{m}$ (FSSP), are shown in the top panel and the larger $>50 \mu \mathrm{m}(\mathrm{CPI})$ in the bottom panel.

The cirrus ice crystal number concentration in the FSSP interval ranges between $0.08-0.5$, with distinct peaks up to $2 / 10 \mathrm{~cm}^{-3}$ at $9.1 / 9.4 \mathrm{~km}$, respectively, corresponding with enhanced supersaturation (see Fig. 6, bottom). Here, new ice crystal formation may take place. Comparing the FSSP number concentration of cirrus clouds to that of contrails, it becomes obvious that $N_{\text {ice }}$ is enhanced in the contrail to values close to $100 \mathrm{~cm}^{-3}$, as expected for contrails. This feature disappears when regarding the size interval $>50 \mu \mathrm{m}$, i.e. only the smallest ice crystals are enhanced in number and are most probably formed by the contrail itself. With up to about $10 \mu \mathrm{m}$, the sizes are in good agreement with other measurements of contrail ice crystals (Schröder et al., 2000; Febvre et al., 2009; Schumann et al., 2010).

Now we investigate the larger size interval, where the concentration of the ice crystals is much less than for the smaller sizes. Here, $N_{\text {ice,contrail }} \approx N_{\text {ice,cirrus }}$, indicating that the large ice crystals in the contrail were entrained by the surrounding cirrus clouds. The highest concentrations of the larger ice crystals are found in the lowermost, subsaturated part of the cirrus layer, where the contrail is also placed (see Fig. 6, bottom). This is likely due to sedimentation of large ice particles from higher altitudes.

To obtain a more detailed picture of the vertical structure of the atmosphere, ECMWF analysis data was interpolated linearly in space to the Falcon flight track. The analyses were available four times daily (00:00, 06:00, 12:00 and 18:00 UTC) at a resolution of $0.25^{\circ}$ in the horizontal and 91 hybrid sigma-pressure levels in the vertical direction. Figure 8 shows cross-sections of model cloud ice water content (CIWC), relative humidity over ice and vertical velocity of the 12:00 UTC analysis on 17 November. The three in-situ detected cirrus periods and the encountered contrail are highlighted in red. The cirrus clouds, which were observed as 

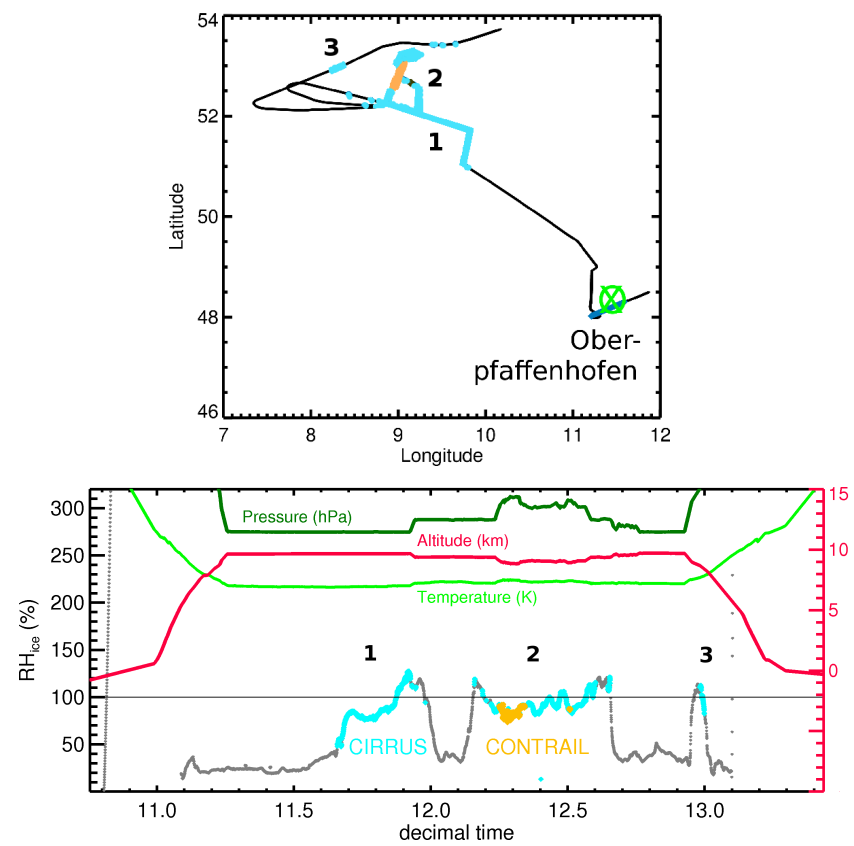

Fig. 5. Survey of DLR Falcon's 1st flight on 17 November2008, 11:00 to 13:20 UTC. Top panel: flight path, turquoise/orange indicate cirrus/contrails. Bottom panel: temperature, pressure, altitude and $\mathrm{RH}_{\text {ice }}$ along the flight path. DLR Falcon crossed three cirrus sections, labeled $1-3$ in the following.
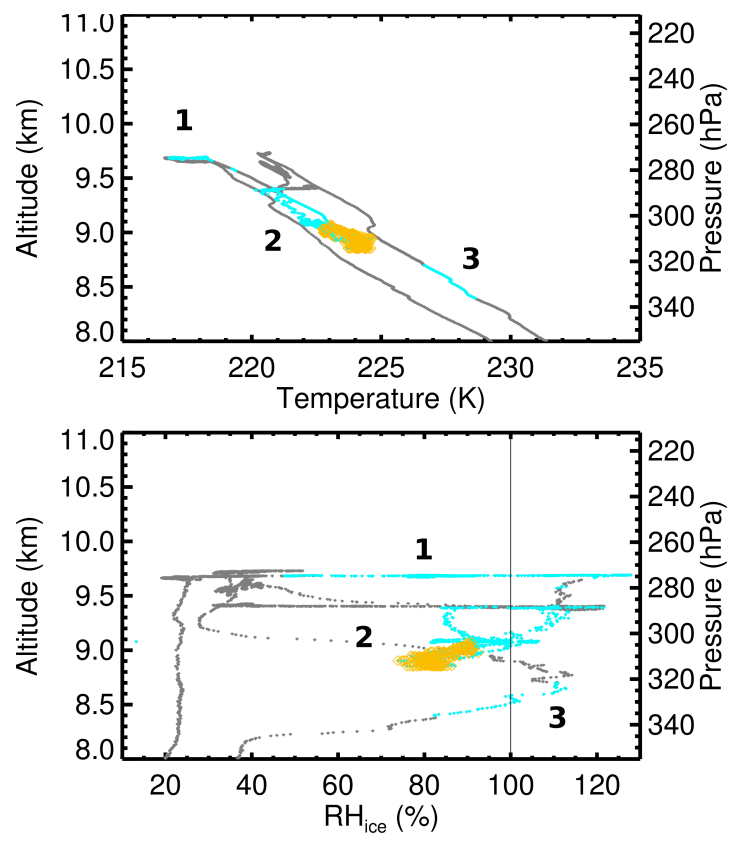

Fig. 6. Vertical profiles of cirrus (turquoise) and contrail (orange) temperature and $\mathrm{RH}_{\mathrm{ice}}$ during the 1st flight on 17 November 2008. Cirrus periods 1: 11:40-11:55 UTC, 2: 12:10-12:40 UTC (including the A340 contrail) and 3: around 13:00 UTC.

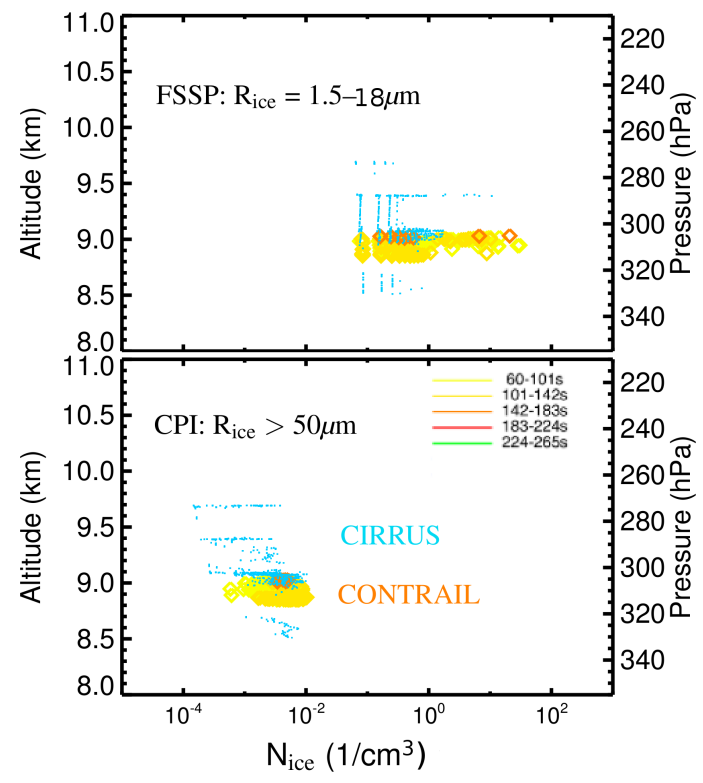

Fig. 7. Vertical profiles of the ice crystal number $N_{\text {ice }}$ for different size intervals in the 2 . cirrus (turquoise) period of the 1 st flight on 17 November 2008, including the A340 contrail (coloured by age, see legend in bottom panel). Cloud particle instrumentation: FSSP - Forward Scattering Spectrometer Probe and CPI - Cloud Particle Imager, for more information see Sect. 2.

thin and nearly subvisible (see Sect. 3.1), are characterized by very small CIWC in the model (less than 3 ppmw).

Comparing now the measured $\mathrm{RH}_{\text {ice }}$ (Fig. 5, bottom) with that derived from the ECMWF data fields yields a very good agreement. Focusing on the time intervals of cirrus detection, it becomes clear that the large ice crystals in the subsaturated cirrus and contrail shown in Fig. 7 (bottom) are likely not connected to new ice formation in the overlying supersaturated region, since this supersaturation takes place only in a part of the cirrus, while the large crystals are found almost always when cirrus are detected.

Inspection of the vertical velocity field in the cirrus layer yields small values between zero and $-2 \mathrm{~cm} \mathrm{~s}^{-1}$, suggesting a weak synoptic scale descent of the air mass, which has most likely caused the slight subsaturation in the cirrus. The complete history of the cirrus detected in the second time interval will be investigated in the next section.

\section{Model simulations of thin/subvisible cirrus}

To study the occurrence of large ice crystals in a subsaturated environment, we performed a model case study of the cirrus probed on 17 November 2008, described in the previous section. Further, idealized model simulations of cirrus cycles, including growth and evaporation times of ice crystals are performed, covering the complete cirrus temperature (180 $240 \mathrm{~K})$ and vertical velocity $\left(1-1000 \mathrm{~cm} \mathrm{~s}^{-1}\right)$ range. 


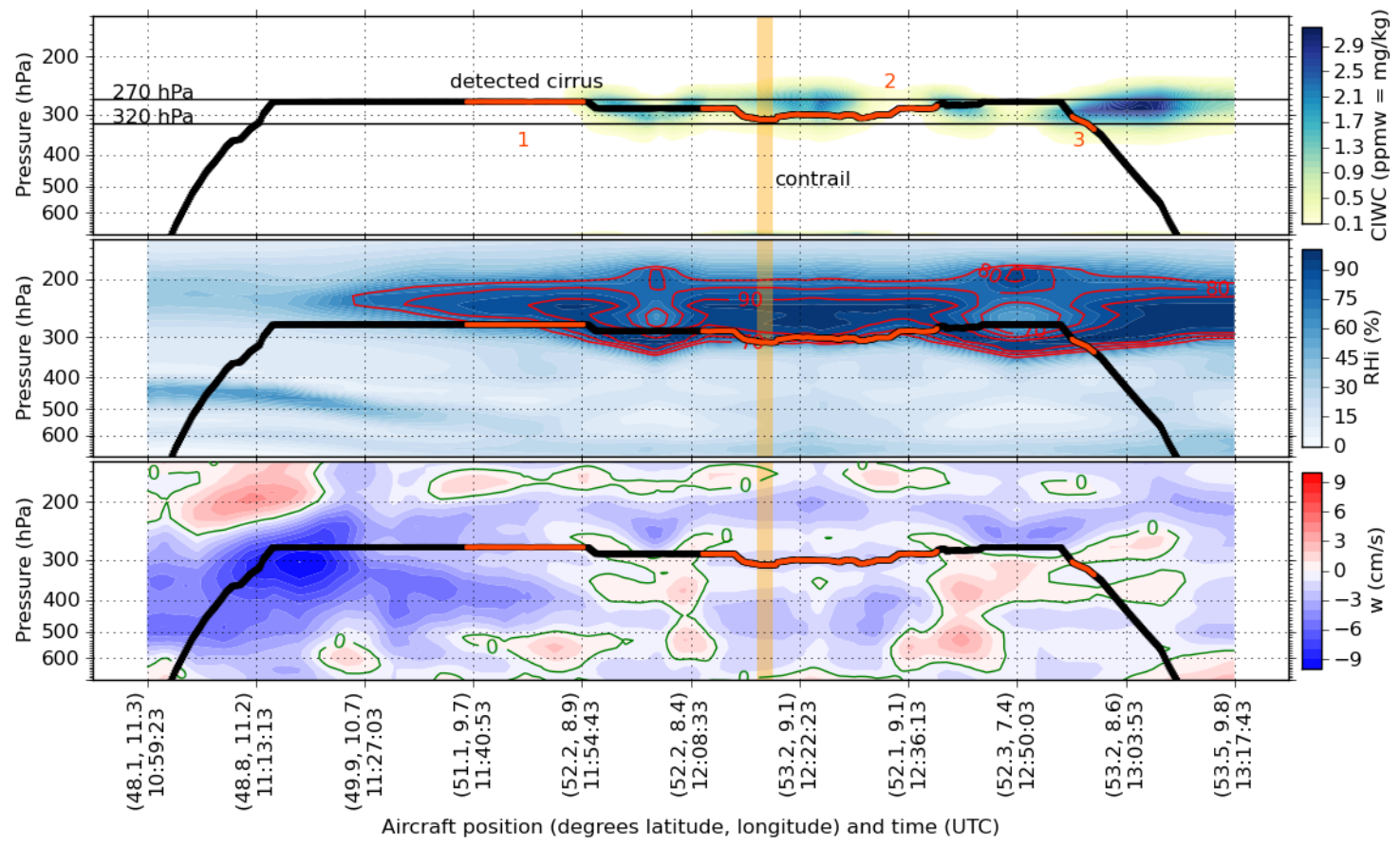

Fig. 8. Vertical cross sections of ECMWF analyzed cloud ice water content (CIWC), $\mathrm{RH}_{\text {ice }}$ and vertical velocity $(w)$ on 17 November 2008 , 12:00 UTC along the flight route. The in-situ detected cirrus periods are highlighted in red on the flight profile. The time of the contrail event is indicated by the orange bar.

The kinetical microphysical MAID (Bunz et al., 2008) was used for that purpose. MAID was developed especially to balance exactly trace gas components between the gas phase, ice and aerosol particles. The microphysical ice processes implemented in MAID are as follows: homogeneous freezing after Koop et al. (2000), heterogeneous freezing after Kärcher and Lohmann (2003), selectable heterogeneous freezing thresholds varying with temperature and variable number of ice nuclei (Gensch et al., 2008), diffusional growth, accomodation of water on ice $\alpha=1$, evaporation, sublimation and Lagrangian ice particle tracking. Sedimentation of ice crystals is not yet included in MAID.

\subsection{Case study: flight 17 November 2008}

The evolution of the large ice crystals in the thin cirrus probed on 17 November 2008 is investigated by running MAID along air mass trajectories ending at the point of cirrus observation, as described by Gensch et al. (2008).

Therefore, $50 \mathrm{~h}$ backward air mass trajectories are calculated from the ECMWF wind fields in different pressure levels - covering the observed cirrus cloud layer-, starting approximately at the geographical coordinates of contrail detection over Hamburg (see Fig. 5, bottom). The trajectories are shown in Fig. 9 and marked by the pressure at the point of contrail detection.
Two bundles of trajectories can be seen, one starting at about $58^{\circ} \mathrm{N},-60^{\circ} \mathrm{E}$, the other around $30^{\circ} \mathrm{N},-40^{\circ} \mathrm{E}$. The turquoise dots are plotted where cirrus are present in the ECMWF analysis data. The temperature and pressure histories of the trajectories are shown in Fig. 10. At $310 \mathrm{hPa}$, the level of cirrus and contrail detection, the measured temperature and pressure is in good agreement with the ECMWF values (see red/green dot). The vertical velocities (not shown here) range between around -5 and $5 \mathrm{~cm} \mathrm{~s}^{-1}$ along the trajectory, in accordance with Fig. 8 (bottom panel).

Two different MAID simulations are now performed along each air mass trajectory, the first assuming that the cirrus forms via homogeneous freezing, while heterogeneous freezing is allowed to occur prior to the homogeneous in the second simulation. The ice nuclei (IN) in the heterogeneous case are very efficient, i.e. they freeze at supersaturations over ice of about $110 \%$ (Gensch et al., 2008). Thus, the upper and lower $\mathrm{RH}_{\text {ice }}$ thresholds to trigger freezing are enclosed by the simulations. A mean number of IN $\left(0.01 \mathrm{~cm}^{-3}\right)$ is chosen following DeMott et al. (2010). The amount of water at the beginning of the model simulations is retrieved from the ECMWF data.

The number and size (mean mass radius) of the ice crystals are plotted versus the trajectory time in Fig. 11 (left, blue: $N_{\text {ice }}$, turquoise: $R_{\text {ice }}$ ) while in the right panel $\mathrm{RH}_{\text {ice }}$ is shown (blue line). The homogeneous case is plotted as solid line, the heterogeneous case as dotted line. It can be seen that cirrus clouds form in all pressure levels, with earlier times 


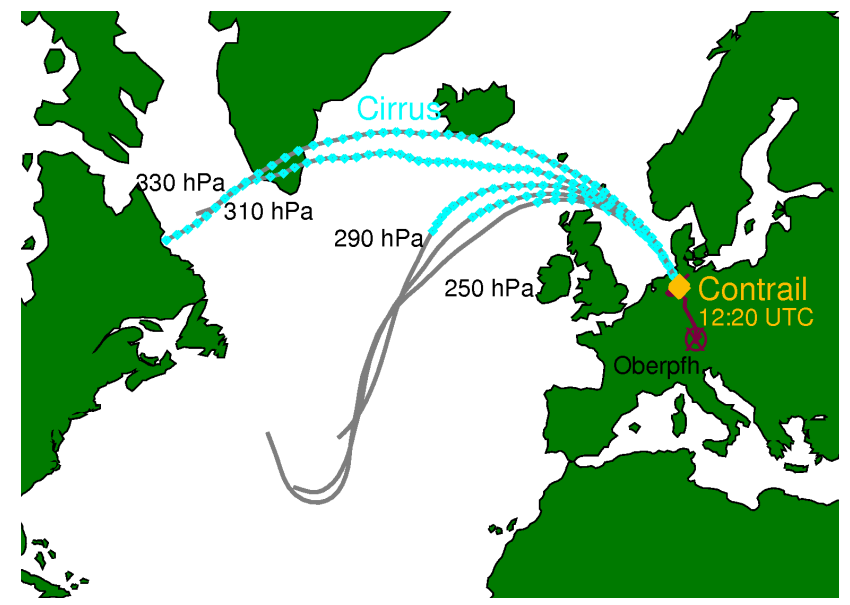

Fig. 9. ECMWF air mass trajectories in different pressure levels, starting approximately at the geographical coordinates of contrail detection on 17 November 2008; turquoise dots represent ECMWF ice.

of formation in case the cirrus would have formed heterogeneously, which is most probable since IN are always present. The heterogeneous and homogeneous ice crystal numbers do not differ greatly, because under the prevailing low vertical velocity homogeneous freezing produces only slightly more ice crystals than heterogeneous ice nucleation. Note here that the model simulations does not represent the real evolution of the cirrus since sedimentation of ice crystals is not yet included in the model. In reality, the ice crystals fall out of one layer to the next, $\mathrm{RH}_{\text {ice }}$ will rise again and new ice nucleation may happen. But, the general structure of the frontal cirrus is represented by the study.

The cirrus form latest at the $250 \mathrm{hPa}$ level and the sooner the lower the altitude, in good agreement with the ECMWF occurrence of ice (Fig. 9). The sizes are at least $50 \mu \mathrm{m}$ in radius throughout the cirrus layer, the numbers are in accordance with the observed ice crystal numbers larger than about $10 \mu \mathrm{m}$ (see Fig. 7). The observed higher number of small ice crystals is not represented in the model simulations because they are probably a consequence of small scale temperature fluctuations not included in the ECMWF fields. $\mathrm{RH}_{\text {ice }}$ is around saturation or larger in all levels until shortly before the point of observation. At $310 \mathrm{hPa}$, where the cirrus and the contrail are detected, thick dots mark the range of observations, in good agreement with the model results. Taking into account sedimentation, $50 \mu \mathrm{m}$ ice crystals fall about $720 \mathrm{~m} \mathrm{~h}^{-1}$ (after Pruppacher and Klett, 1997). Thus, we believe that the observed large ice crystals originate from the highest level which is about $1300 \mathrm{~m}$ above the point of observation. The origin of the air masses is the middle Atlantic between Florida and the Canary Islands and the ice crystals formed probably northerly of Scotland, in good agreement with ECMWF ice occurence (see Fig. 9, turquoise dots at the $250 \mathrm{hPa}$ trajectory). After formation, the air rises further

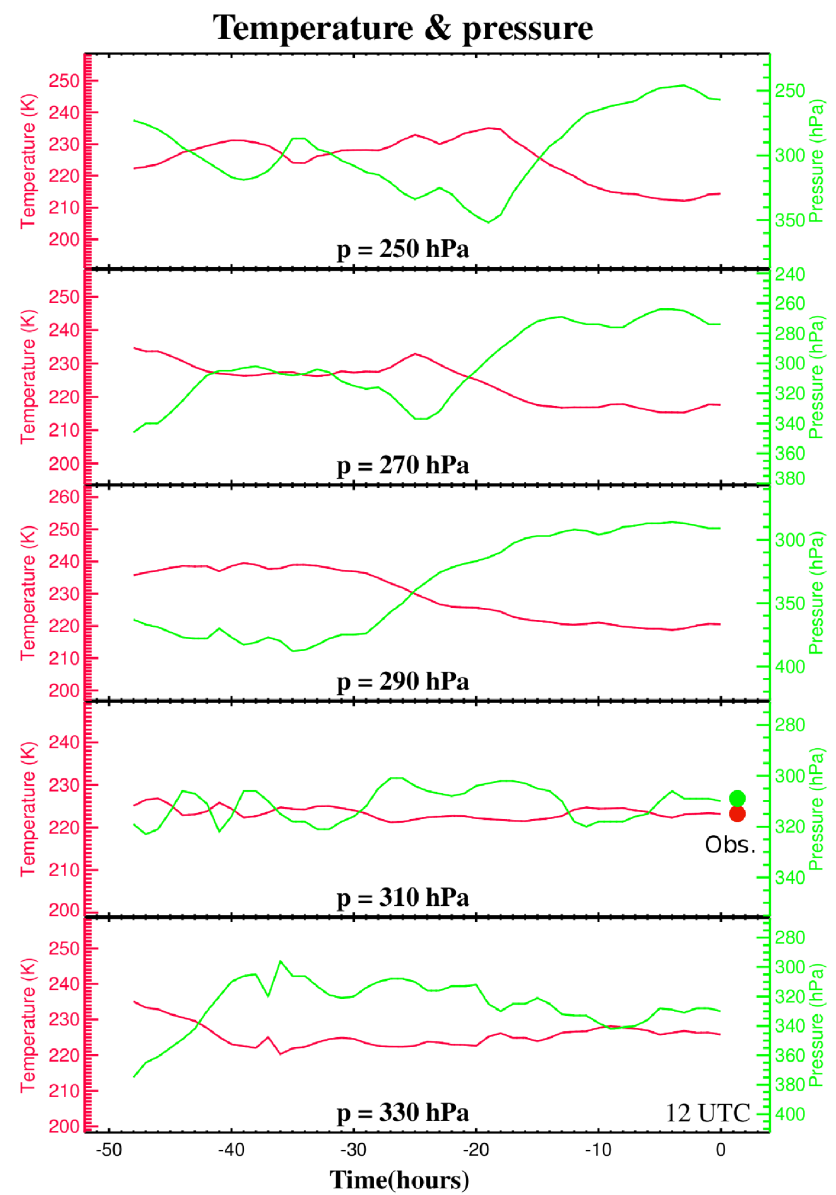

Fig. 10. Temperature and pressure along the trajectories shown in Fig. 9, ending at the point of contrail detection at $310 \mathrm{hPa}$. In the $310 \mathrm{hPa}$ panels, big dots denotes the observations (see Figs. 5 and 6).

with a slow updraft, ideal conditions for the crystals to grow to larger sizes in the time period of several hours. From a certain size on they have fallen through the slightly supersaturated layer while further growing until they were detected in the cirrus -and, after mixing, in the aircraft contrail- shortly after they reached, still existing, the slightly subsaturated region.

\subsection{Cirrus ice growth and evaporation times}

From the case study presented in the last section the question arised, if the time cirrus clouds can exist in a subsaturated environment may represent a substantial part of their total lifetime. Nelson (1998) stated that "the time for an initially solid polyhedral crystal to completely lose all facets ... is calculated to be approximately $50 \%$ of the crystal's total lifetime independent of ... the undersaturation." 

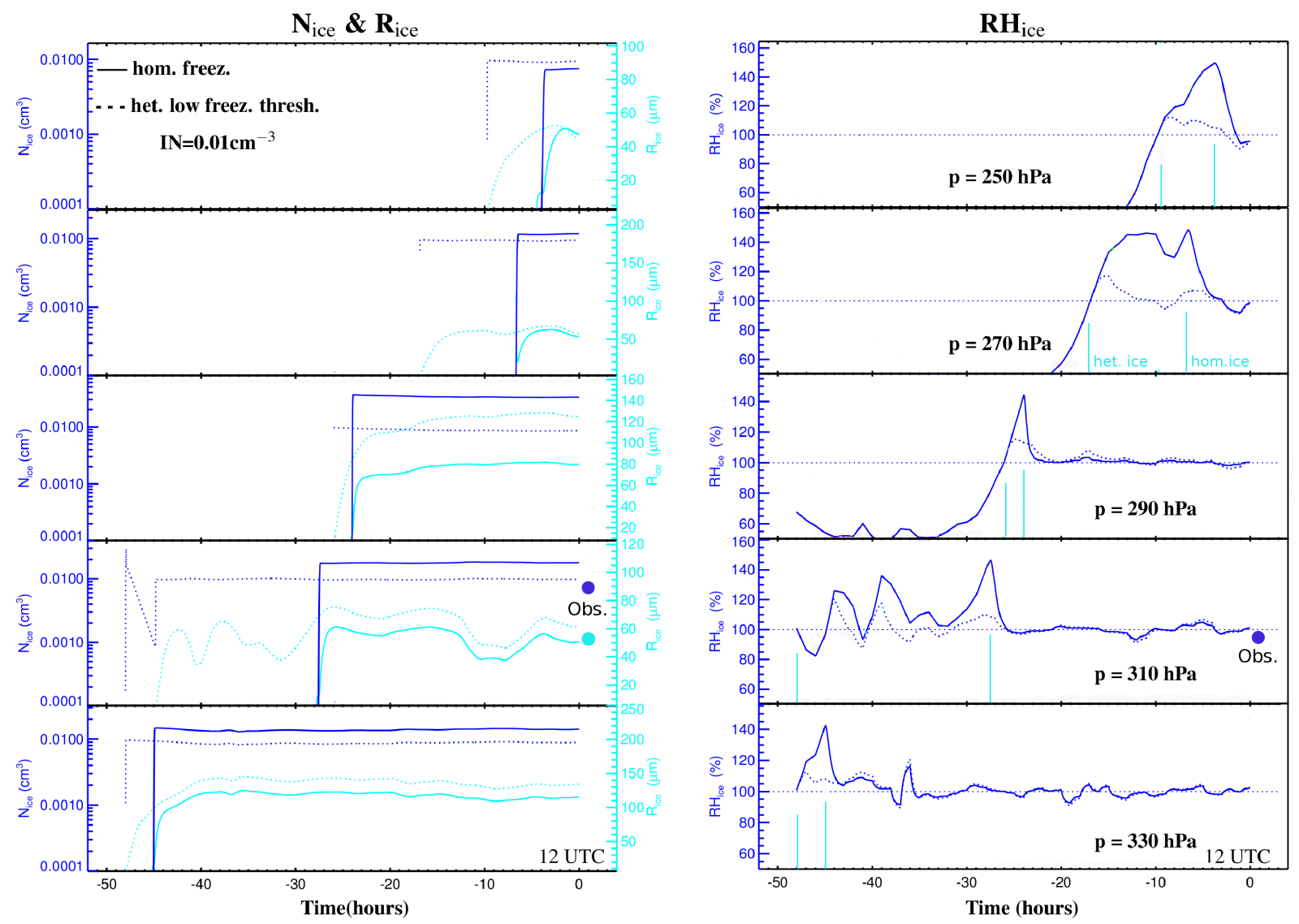

Fig. 11. MAID simulations along the trajectories shown in Figs. 9 and 10 (solid line: homogeneous freezing, dotted line: heterogeneous freezing); $N_{\text {ice,MAID }}$ : number, $R_{\text {ice,MAID }}$ : mean mass size of ice crystals. In the $310 \mathrm{hPa}$ panels, big dots denotes the observations $\left(N_{\text {ice, obs }}\right.$ : peak number, $R_{\text {ice,obs }}$ : approximate size of ice crystals, see Fig. 7, bottom panel; $\mathrm{RH}_{\text {ice }}$ see Fig. 6).

To evaluate in more detail the times that ice crystals can live in a subsaturated environment, we performed a series of idealized simulations of cirrus cycles. We simulated heterogeneous and homogeneous ice formation, crystal growth and evaporation over a wide range of temperatures (190-240 K, in $10 \mathrm{~K}$ steps) and vertical velocities (1$1000 \mathrm{~cm} \mathrm{~s}^{-1}=$ cooling rates $0.36-360 \mathrm{~K} \mathrm{~h}^{-1}$ ) and analyzed the crystal growth and evaporation times. The initial amount of water is set to $90 \%$ of the saturation value of the respective temperature.

Each ice cycle is simulated as follows: first, constant cooling with the prescribed vertical velocity leads to ice formation. After ice formation, the crystals are allowed to grow in dynamical equilibrium (i.e. constant $\mathrm{RH}_{\text {ice }}$ while further cooling, where the water vapor excess caused by the cooling is directly transported to the ice crystals) until the change in size is only very small. This time we refer to as ice crystal growth time (see Fig. 12, bottom panel). Then, the ice crystals are evaporated by heating with the same rate as the previous cooling. The heating of the air parcel was prescribed instead of letting the ice crystals evaporate in a layer of constant $\mathrm{RH}_{\text {ice }}$ to simulate the effect of sedimentation of the ice crystals into warmer layers of air $^{2}$. The time between the start of the heating and the disappearance of the last ice crystal we refer to as evaporation time.

Before discussing the growth and evaporation times resulting from the model studies, we want to note that in reality cooling or heating of the air is not constant and not the same for a cloud, sedimentation of ice crystals influence the development of the cloud and the ice cloud may never reach or even live in dynamical equilibrium (see also recent results of Spichtinger and Cziczo, 2010). Further, the ice crystal sizes and the growth and evaporation times vary with the amount of available water (lowering the available water would lead to smaller ice crystals and shorter growth/evaporation times). But, keeping this in mind the idealized model simulations give a good impression on ice crystal growth and evaporation times.

\footnotetext{
${ }^{2}$ Note: in another set of simulations the heating rates were adjusted to the temperature change the falling ice crystals with respective mean sizes would experience. The results does not greatly change the picture of ice growth and evaporation times.
} 

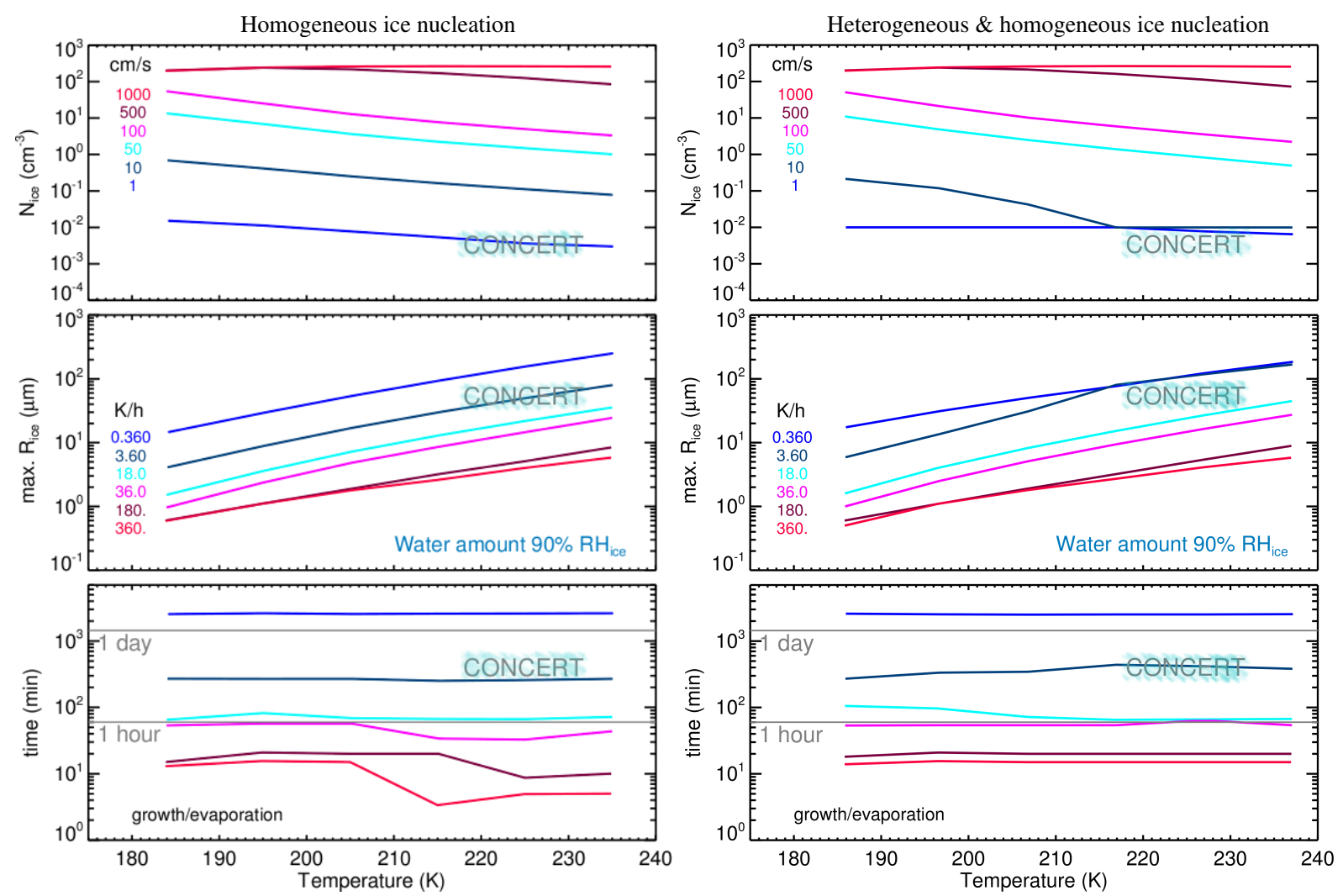

Fig. 12. Ice crystal number (top), maximum size (middle) and growth/evaporation times (bottom) in dependence on temperature and cooling rate ( $\sim$ vertical velocity): idealized model simulations performed with MAID assuming pure homogeneous (left) and heterogeneous and homogeneous (right) freezing as ice nucleation mechanism. The initial conditions of the model runs are as follows: pressure $=f(T)($ Schiller et al., 2008), particle number $=300 \mathrm{~cm}^{-3}$, mean particle radius $0.2 \mu \mathrm{m}$. The heating rates during evaporation correspond to the respective cooling rates. The range of observations during CONCERT are indicated in grey letters.

In Fig. 12 the ice crystal numbers (top panel), their maximum sizes in dynamical equilibrium (middle panel) and their growth/evaporation times (bottom panel) are shown in dependence on temperature for different vertical velocities (cooling rates). Growth and evaporation times are nearly identical in the simulations due to the identical cooling and heating rates prescribed in the simulations and are thus shown only once here. In the left panel the results for pure homogeneous freezing are shown, while in the right panel heterogeneous freezing act as ice initiator, followed by homogeneous freezing in cases the respective freezing $\mathrm{RH}_{\text {ice }}$ is achieved again. The lowest cooling rate $\left(0.36 \mathrm{~K} \mathrm{~h}^{-1}=1 \mathrm{~cm} \mathrm{~s}^{-1}\right.$, blue) is typical for cirrus clouds evolving in frontal systems, whereas the highest cooling rate $\left(360 \mathrm{~K} \mathrm{~h}^{-1}=1000 \mathrm{~cm} \mathrm{~s}^{-1}\right.$, red) may occur in convective cirrus clouds.

The number of ice crystals is highest for the lowest temperatures and highest vertical velocities (see also e.g. Kärcher and Lohmann, 2002). The mean crystal size is inversely proportional to the ice crystal number and the available water vapor, which increases with the temperature in our simulations (and approximately also in the atmosphere). This means that ice crystals can grow to larger sizes when the number is low and amount of water is high, because more water is distributed among less ice crystals. Hence, in our scenarios the maximum ice crystal size increases with decreasing vertical velocity and increasing temperature.

Comparing the cirrus that formed homogeneously with those where heterogeneous freezing is allowed to occur first show that the strongest effect happens for the lowest vertical velocities (see also Kärcher and Lohmann, 2003). At $1 \mathrm{~cm} \mathrm{~s}^{-1}$, the ice crystal concentration is always equal to the IN number, at $10 \mathrm{~cm} \mathrm{~s}^{-1}$ this is true for temperatures higher than about $215 \mathrm{~K}$. For lower temperatures, subsequent homogeneous freezing rises the ice crystal number, but not to the same amount than in the pure homogeneous case. Accordingly, the ice crystals are slightly smaller.

In the evaporation phase, the model simulations show that the water emerging from the ice crystals keeps the ambient relative humidity $\mathrm{RH}_{\text {ice }}$ slightly below saturation in spite of continuous heating most of the time. Only if they shrink to small sizes, $\mathrm{RH}_{\text {ice }}$ decreases rapidly and the crystals evaporate completely. The growth and evaporation times are on the order of minutes when many small crystals are 
present (as for example in contrails) and increase to the timescale of hours with increasing crystal size and decreasing number. Longer growth and evaporation times - as indicated for $1 \mathrm{~cm} \mathrm{~s}^{-1}$ updraft- are unrealistic in the atmosphere, because the large ice crystals will sediment out. The growth/evaporation times are very similar for the pure homogeneous and the heterogeneous \& homogeneous case, which is not surprising because the ice crystals have approximately the same size. It seems to be surprising that the times for growth/evaporation do not change with temperature, but keeping in mind that the total amount of ice decreases with temperature, it becomes obvious that the times per ice unit are getting longer accordingly.

The cirrus conditions found during CONCERT are indicated by the blue-grey "CONCERT" in Fig. 12. As discussed in Sect. 3.1, these cirrus were thin/subvisible by eye from aircraft. The time they need to grow to the maximum size is in the order of several hours and they can survive while shrinking around the same time in a subsaturated environment. However, the lifetime of these cirrus is dependent on the vertical distribution of super- and subsaturation, because the crystals sediment out in accordance with their size.

In a previous model study of subvisible cirrus, Kärcher (2002) concluded that longer lived ( $>10 \mathrm{~min}$ ) subvisible cirrus are generated only within a narrow range of updraft speeds below $1-2 \mathrm{~cm} \mathrm{~s}^{-1}$ at temperatures below about $215 \mathrm{~K}$. This conclusion is based on a cirrus thickness of $750 \mathrm{~m}$ and an optical extinction criterion tighter than the visibility by eye from aircraft (see Sect. 3.1). But, classifying cirrus thickness from visibility from aircraft (see also Sect. 3.1) it follows, that thin/subvisible cirrus can exist for vertical velocities $\leq 10 \mathrm{~cm} \mathrm{~s}^{-1}$ in the complete cirrus temperature range.

\section{Summary and conclusions}

During the airborne field campaign CONCERT, which took place in October/November 2008 over Northern Europe, the properties of cirrus and contrails and their environment were measured on board of the DLR Falcon. The predominant meteorological situation throughout the flights were frontal systems regularly crossing central Europe. Contrails were mainly probed above mid-level warm clouds. Observations of $\mathrm{RH}_{\text {ice }}$ under these conditions revealed that the flights were mostly performed in subsaturated, evaporating thin/subvisible cirrus and contrails embedded therein. Few, but large ice crystals up to $50 \mu \mathrm{m}$ radius and larger were detected inside of both the cirrus and the contrails.

Detailed analysis of the situation with the assistance of observations and model simulations showed that the few large crystals formed and grew in the slightly supersaturated low ascent regions of the frontal systems, then sedimented into a subsaturated layer, where the crystals are mixed into the contrails. Further model simulations revealed that such thin/subvisible ice clouds can live in subsaturated air for a couple of hours, in dependence on the thickness of the subsaturated layer.

Jensen and et al. (2001) studied subvisible cirrus in supersaturated air by model simulations and stated that "there is a potential for a climatically important class of optically thin cirrus in supersaturated regions". In a study of Gierens et al. (2000), strong indication that subvisible cirrus is associated to ice supersaturated regions was found for the northern midlatitude upper troposphere. Gierens et al. (2000) already pointed out that a decoupling of subvisible cirrus from ice supersaturated regions may occur, since sedimenting ice crystals could fall out of the supersaturated region into subsaturated air. Here, we show experimental evidence for the existence of this type of thin/subvisible cirrus.

Thin/subvisible cirrus appear in high as well as low pressure systems and thus might represent a considerable part of the mid-latitude cirrus coverage. On this larger scale, a consequence of our findings is that the coverage of thin/subvisible cirrus in subsaturated air might be not negligible. Krämer et al. (2009) presented frequencies of occurrence of $\mathrm{RH}_{\text {ice }}$ inside of cirrus derived from a large airborne in-situ data set. Though subsaturated cirrus exist in their observations, the thin/subvisible cirrus in general and specifically those under subsaturated conditions may be underrepresented because they are hard to find by aircraft or even not detectable by in-situ instrumentation.

Immler et al. (2008) studied thin/subvisible ice clouds and contrails in high pressure systems over Germany on the basis of ground based Lidar observations, which are much more sensitive to this type of ice clouds than in-situ instruments. They concluded that "cirrus and contrails are generally present where the upper troposphere is supersaturated with respect to ice".

Here, we suggest to quantify in future studies the contribution of thin/subvisible cirrus in subsaturation to the total cirrus coverage to assess their importance for the impact of cirrus on climate.

Acknowledgements. We greatly acknowledge Andreas Dörnbrack for excellent analysis of the meteorological situation during CONCERT, Klaus Gierens for fruitful discussions about contrail formation and development and Dominik Schäuble for great assistance with the campaign. Thanks are given to Eric Jensen who provides computer code to calculate contrail thermodynamics. Further, we thank the Falcon team operating the aircraft for their support and the DLR flight department for providing the meteorological parameters, as well as the Deutsche Flugsicherung (DFS) and the Deutsche Lufthansa for excellent help during the campaign. The CONCERT campaign was organized by the Junior research group AEROTROP and in part financed by the DLR project CATS (Climate optimized air traffic system).

Edited by: T. Garrett 


\section{References}

Borrmann, S., Luo, B., and Mishchenko, M.: Application of the T-matrix method to the measurement of aspherical (ellipsoidal) particles with forward scattering optical particle counters., J. Aerosol Sci., 31, 89-799, 2000.

Bunz, H., Benz, S., Gensch, I., and Krämer, M.: MAID: a model to simulate UT/LS aerosols and ice clouds, Environ. Res. Lett., 3, 035001, doi:10.1088/1748-9326/3/3/035001, 2008.

Burkhardt, U., Kärcher, B., and Schumann, U.: Global modeling of the contrail and contrail cirrus climate impact, B. Am. Meteorol. Soc., 91, 479-484, doi:10.1175/2009BAMS2656.1, 2010.

de Reus, M., Borrmann, S., Bansemer, A., Heymsfield, A. J., Weigel, R., Schiller, C., Mitev, V., Frey, W., Kunkel, D., Kürten, A., Curtius, J., Sitnikov, N. M., Ulanovsky, A., and Ravegnani, F.: Evidence for ice particles in the tropical stratosphere from in-situ measurements, Atmos. Chem. Phys., 9, 6775-6792, doi:10.5194/acp-9-6775-2009, 2009.

DeMott, P. J., Cziczo, D., Prenni, A., Murphy, D., Kreidenweis, S., Thomson, D., Borys, R., and Rogers, D.: Measurements of the concentration and composition of nuclei for cirrus formation, $\mathrm{P}$. Natl. Acad. Sci. USA, 100, 14660-14655, 2003.

DeMott, P. J., Prenni, A. J., Liu, X., Kreidenweis, S. M., Petters, M. D., Twohy, C. H., Richardson, M. S., Eidhammer, T., and Rogers, D. C.: Predicting global atmospheric ice nuclei distributions and their impacts on climate, P. Natl. Acad. Sci. USA, 107, 11217-11222, doi:10.1073/pnas.0910818107, 2010.

Febvre, G., Gayet, J.-F., Minikin, A., Schlager, H., Shcherbakov, V., Jourdan, O., Busen, R., Fiebig, M., Kärcher, B., and Schumann, U.: On optical and microphysical characteristics of contrails and cirrus, J. Geophys. Res., 114, D02204, doi:10.1029/2008JD010184, 2009.

Forster, P. and Rogers, H.: Metrics for comparison of climate impacts from well mixed greenhouse gases and inhomogeneous forcing such as those from UT/LS ozone, contrails and contrail cirrus, Aviation Climate Change Research Initiative (ACCRI), 1-57, 2008.

Gayet, J.-F., Asano, S., Yamazaki, A., Uchiyama, A., Sinyuk, A., Jourdan, O., and Auriol, F.: Two case studies of winter continental-type water and mixed-phase stratocumuli over the sea 1. Microphysical and optical properties, J. Geophys. Res., 107, 4569, doi:10.1029/2001JD001106, 2002a.

Gayet, J.-F., Auriol, F., Minikin, A., StrÃ đm, J., Seifert, M., Krejci, R., Petzold, A., Febvre, G., and Schumann, U.: Quantitative measurement of the microphysical and optical properties of cirrus clouds with four different in situ probes: Evidence of small ice crystals, Geophys. Res. Lett., 29, 2230, doi:10.1029/2001GL014342, 2002b.

Gensch, I., Bunz, H., Baumgardner, D., Christensen, L., Fahey, D., Hermann, R., Lawson, P., Popp, P., Smith, J., Webster, C., Weinstock, E., Wilson, J., Peter, T., and Krämer, M.: Supersaturations, microphysics and nitric acid partitioning in a cold cirrus observed during CR-AVE 2006: an observation-modeling intercomparison study., Environ. Res. Lett., 3, 035003, doi:10.1088/17489326/3/3/035003, 2008.

Gettelman, A., Fetzer, E., Eldering, A., and Irion, F.: The Global Distribution of Supersaturation in the Upper Troposphere from the Atmospheric Infrared Sounder, J. Climate, 19, 6089-6103, 2006.

Gierens, K. and Spichtinger, P.: On the size distribution of ice- supersaturated regions in the upper troposphere and lowermost stratosphere, Ann. Geophys., 18, 499-504, doi:10.1007/s00585000-0499-7, 2000.

Gierens, K., Schumann, U., Helten, M., Smit, H., and Marenco, A.: A distribution law for relative humidity in the upper troposphere and lower stratosphere derived from three years of MOZAIC measurements, Ann. Geophys., 17, 1218-1226, doi:10.1007/s00585-999-1218-7, 1999.

Gierens, K., Schumann, U., Helten, M., Smit, H., and Wang, P.: Ice-supersaturated regions and subvisible cirrus in the northern midlatitude upper troposphere , J. Geophys. Res., 105, 2274322753, 2000.

Immler, F., Treffeisen, R., Engelbart, D., Krüger, K., and Schrems, O.: Cirrus, contrails, and ice supersaturated regions in high pressure systems at northern mid latitudes, Atmos. Chem. Phys., 8, 1689-1699, doi:10.5194/acp-8-1689-2008, 2008.

Jensen, E., Toon, O., Kinne, S., Sachse, G., Anderson, B., Chan, K., Twohy, C., Gandrud, B., Heymsfield, A., and Miake-Lye, R.: Environmental conditions required for contrail formation and persistence, J. Geophys. Res., 103, 3929-3936, 1998.

Jensen, E., Toon, O., Vay, S., Ovarlez, J., May, R., Bui, T. P., Twohy, Gandrud, B., Pueschel, R. F., and Schumann, U.: Prevalence of ice-supersaturated regions in the upper troposphere: Implications for optically thin ice cloud formation, J. Geophys. Res., 106, 17253-17266, 2001.

Koop, T.: Homogeneous ice nucleation in water and aqueous solutions, Z. Phys. Chem., 218, 1231-1258, 2004.

Koop, T., Luo, B., Tsias, A., and Peter, T.: Water activity as the determinant for homogeneous ice nucleation in aqueous solutions, Nature, 406, 611-614, 2000.

Korolev, A., Emery, E., Strapp, J., Cober, S., Isaac, G., Wasey, M., and Marcotte, D.: Small ice particles in tropospheric clouds: fact or artifact? Airborne Icing Instrumentation Evaluation Experiment, B. Am. Meteorol. Soc., 92, doi:10.1175/2010BAMS3141.1, 2011.

Krämer, M. and Hildebrandt, M.: The role of heterogeneous freezing in cirrus formation: new model sensitivity studies, AMS Cloud Physics Conference, Portland, USA, 2010.

Krämer, M., Schiller, C., Afchine, A., Bauer, R., Gensch, I., Mangold, A., Schlicht, S., Spelten, N., Sitnikov, N., Borrmann, S., de Reus, M., and Spichtinger, P.: Ice supersaturations and cirrus cloud crystal numbers, Atmos. Chem. Phys., 9, 3505-3522, doi:10.5194/acp-9-3505-2009, 2009

Kärcher, B.: Properties of subvisible cirrus clouds formed by homogeneous freezing, Atmos. Chem. Phys., 2, 161-170, doi:10.5194/acp-2-161-2002, 2002.

Kärcher, B. and Lohmann, U.: A parameterization of cirrus cloud formation: homogeneous freezing of supercooled aerosols, J. Geophys. Res., 107, 4010, doi:10.1029/2002JD003220, 2002.

Kärcher, B. and Lohmann, U.: A parameterization of cirrus cloud formation: heterogeneous freezing, J. Geophys. Res., 108, 4402, doi:10.1029/2002JD003220, 2003.

Marti, J. and Mauersberger, K.: A survey and new measurements of ice vapour pressure at temperatures between $170 \mathrm{~K}$ and $250 \mathrm{~K}$, Geophys. Res. Lett., 20, 363-366, 1993.

Nelson, J.: Sublimation of Ice Crystals, J. Atmos. Sci., 55, 910-919, 1998.

Petzold, A., Busen, R., Schröder, F., Baumann, R., Kuhn, M., Ström, J., Hagen, D., Whitefield, P., Baumgardner, D., Arnold, 
F., Borrmann, S., and Schumann, U.: Near-Field measurements on contrail properties from fuels with different sulfur content, J. Geophys. Res., 102, 29867-29880, 1997.

Pruppacher, H. and Klett, J.: Microphysics of Clouds and Precipitation, Kluwer Academic, 2nd edn., 1997.

Sassen, K., Griffin, M. K., and Dodd, G. C.: Optical Scattering and Microphysical Properties of Subvisual Cirrus Clouds, and Climatic Implications, J. Appl. Meteorol., 28, 91-98, 1989.

Schiller, C., Krämer, M., Afchine, A., Spelten, N., and Sitnikov, N.: The ice water content in Arctic, midlatitude and tropical cirrus, J. Geophys. Res., 113, D24208, doi:10.1029/2008JD010342., 2008.

Schlager, H., Konopka, P., Schulte, P., Schumann, U., Ziereis, H., Arnold, F., Klemm, M., Hagen, D. E., Whitefield, P. D., and Ovarlez, J.: In situ observations of air traffic emission signatures in the North Atlantic flight corridor, J. Geophys. Res., 102, 10739-10750, doi:10.1029/96JD03748, 1997.

Schröder, F., Kärcher, B., Duroure, C., Ström, J., Petzold, A., Gayet, J.-F., Strauss, B., Wendling, P., and Borrmann, S.: On the transition of contrails into cirrus clouds, J. Atmos. Sci., 57, 464-480, 2000 .

Schumann, U.: On conditions for contrail formation from aircraft exhaust, Meteorol. Zeitschrift, 5, 4-23, 1996.

Schumann, U., Schlager, H., Arnold, F., Baumann, R., Hachberger, P., and Klemm, O.: Dilution of aircraft exhaust plumes at cruise altitudes, Atmos. Environ., 32, 3097-3103, 1998.

Schumann, U., Mayer, B., Gierens, K., Unterstrasser, S., Jessberger, P., Petzold, A., and Voigt, C.: Effective radius of ice particles in cirrus and contrails, J. Atmos. Sci., 68, 300-321, doi:10.1175/2010JAS3562.1, 2010.
Solomon, S., Qin, D., Manning, M., Marquis, M., Averyt, K., Tignor, M. M. B., Miller Jr., R., L., H., and Chen, Z. E.: Climate change 2007, The physical science basis, Cambridge University press, 1 st edn., 2007.

Spichtinger, P. and Cziczo, D. J.: Impact of heterogeneous ice nuclei on homogeneous freezing events, J. Geophys. Res., 115, D14208, doi:10.1029/2009JD012168, 2010.

Spichtinger, P., Gierens, K., and Read, W.: The global distribution of ice supersaturated regions as seen by the microwave limb sounder., Q. J. Roy. Meteor. Soc., 129, 3391-3410, 2003.

Voigt, C., Schlager, H., Ziereis, H., Kärcher, B., Luo, B., Schiller, C., Krämer, M., Popp, P., Irie, H., and Kondo, Y.: Nitric acid in cirrus clouds, Geophys. Res. Lett., 33, L05803, doi:10.1029/2005GL025159, 2006.

Voigt, C., Schumann, U., Jurkat, T., Schäuble, D., Schlager, H., Petzold, A., Gayet, J.-F., Krämer, M., Schneider, J., Borrmann, S., Schmale, J., Jessberger, P., Hamburger, T., Lichtenstern, M., Scheibe, M., Gourbeyre, C., Meyer, J., Kübbeler, M., Frey, W., Kalesse, H., Butler, T., Lawrence, M. G., Holzäpfel, F., Arnold, F., Wendisch, M., Döpelheuer, A., Gottschaldt, K., Baumann, R., Zöger, M., Sölch, I., Rautenhaus, M., and Dörnbrack, A.: In-situ observations of young contrails - overview and selected results from the CONCERT campaign, Atmos. Chem. Phys., 10, 90399056, doi:10.5194/acp-10-9039-2010, 2010.

Zöger, M., Afchine, A., Eicke, N., Gerhards, M.-T., Klein, E., McKenna, D., Mörschel, U., Schmidt, U., Tan, V., Tuitjer, F., Woyke, T., and Schiller, C.: Fast in situ stratospheric hygrometers: A new family of balloon-borne and airborne Lymanphotofragment fluorescence hygrometers, J. Geophys. Res., 104, 1807-1816, 1999. 